\title{
Diversity and the European higher education student: policy influencers' narratives of difference
}

\section{Rachel Brooks, University of Surrey}

\begin{abstract}
Comparative studies of European social policy have pointed to significant differences with respect to the way in which diversity is valued and understood, contrasting nations that have adopted strongly compulsory and integrationist policies with others that have pursued more voluntary and pluralistic approaches. Within the higher education sector specifically, although there have been numerous European-level initiatives to encourage national governments to take action to widen access to university, we know relatively little about how key policy actors conceptualise diversity with respect to the student population, and the extent to which such understandings are shared across national borders. Drawing on in-depth interviews with a range of 'policy influencers' in six European countries and an analysis of relevant policy documents, this article suggests that dimensions of difference are not always valued equally and that, despite policy imperatives promoting higher education homogenisation across the continent, some significant differences between nation-states endure.
\end{abstract}

Keywords: diversity, higher education, Europe, age, social class 


\section{Diversity and the higher education student: an analysis of policy from six European countries}

\section{Introduction}

Comparative studies of European social policy have pointed to significant differences with respect to the way in which diversity is valued and understood, contrasting nations such as Denmark, Germany and Austria, which have adopted forms of ethnic and cultural integration that are strongly compulsory and integrationist, with others such as the UK and Sweden, which have pursued more voluntary and pluralistic policies (Banting and Kymlicka, 2013). Within the higher education (HE) sector specifically, although there have been numerous European-level initiatives to encourage national governments to take action to increase access to HE of traditionally under-represented groups (Pérez Cañado, 2015), we know relatively little about how key policy actors understand diversity with respect to the student population, and the extent to which such conceptualisations are shared across national borders. Although there have been some studies about the understandings of under-represented groups held by professionals working within higher education (e.g. Loveday, 2015; Wilkins and Burke, 2015), these have typically focussed on the level of the institution rather than the state. National perspectives are nevertheless important as they are likely to have a bearing, ultimately, on who is permitted and/or encouraged to access higher education and the nature of the experiences of those who do secure entry. Drawing on in-depth interviews with a range of 'policy influencers' in six European countries and an analysis of relevant policy documents, this article suggests that dimensions of difference are not always valued equally and that, despite policy imperatives promoting higher education homogenisation across the continent, some significant differences between nation-states endure. 


\section{Background}

The concept of 'diversity' within higher education institutions

Over recent years, the concept of diversity has come to underpin many organisational strategies within higher education. Nevertheless, despite its increasing popularity within official documents and among senior managers, various studies have demonstrated the potentially problematic nature of this term, suggesting that, rather than helping to redress inequalities, it can often serve to depoliticise and marginalise work in this area. Deem and Morley (2006) argued, over a decade ago, that while there was evidence of some 'mainstreaming' of equality issues within British higher education institutions (HEIs), their interviews with HE staff suggested that this was rarely connected to issues of social justice. They write: 'Rather, the views expressed are consistent with a depoliticised view of diversity as a managed organisational strategy involving human resource directors, with an emphasis on recognition and tolerance, not structural change to tackle the roots of inequality' (p.197). Indeed, the staff in their study tended to understand equality as primarily about issues related to identity and choice, rather than material conditions, while the policies and strategies that Deem and Morley analysed similarly focused on recognitional and cultural issues rather than redistributional approaches.

More recent studies have also indicated that the concept of diversity, as deployed within many educational institutions, can have the effect of sustaining inequalities (see Talib and Fitzgerald (2015), for example, in relation to the schools sector). On the basis of her analysis of publically-available statements from higher education institutions in New Zealand and the UK, Bowl (2018) contends that commitments to equality have been side-lined in favour of 
those that focus on diversity. She maintains that this linguistic change helps HEIs mediate the tension between 'the need ... to project themselves as strong competitors in a global market and leading contributors to the knowledge economy, while at the same time responding to national policy requirements to widen the social base of higher education' (p.672). In particular, the use of the word diversity instead of equality 'evokes the warmth and harmony of institutional inclusiveness without threatening an elitist ethos', while also evading specification of who is excluded and what action needs to be taken to eliminate this exclusion (Bowl, 2018, p.684). Ahmed (2007) has contended that the use of the concept of diversity by practitioners can also be a means of responding to a perceived 'equality fatigue' within higher education institutions. In some ways, this can be a useful strategy. Indeed, some of the interviewees in Ahmed's study argued that the emergence of a 'diversity framework' had enabled those who had previously worked on equality initiatives to have a stronger institutional voice and to take up more central and visible positions within their organisations: 'diversity enables action because it does not get associated with the histories of struggle evoked by more "marked” terms such as equality and justice' (Ahmed, 2007, p.238). Her interviewees also noted, however, the risks attached to the use of the term; its very fluidity could be exploited so as to block action. Ahmed argues that if diversity is understood merely as 'counting people who look different', it can prevent exposure of social and educational disadvantage and thus block associations with equality.

Similarly, analyses of German higher education policies and practices have emphasised the conceptual ambiguity associated with the term diversity. Although some policies have been introduced in Germany to increase the heterogeneity of the student body and the competence of staff at working in more diverse classrooms, Klein (2016) argues that such measures are relatively narrow in their scope, tending to focus only on migration background and ethnicity 
rather than social class, disability and/or sexual orientation. Moreover, they are not underpinned by either an overall strategy or a coherent concept of diversity. Klein contends that although differences are celebrated, unequal power relations between students (and also staff) from different backgrounds remain obscured. She suggests that while some higher education staff are involved in diversity work because of a commitment to social justice, the more pervasive and influential understanding of the term is as a means of securing advantage in the race for 'excellence' and bolstering human capital. This understanding of diversity thus 'overlooks the fact that the academic system is based upon hegemonic patterns ... leading to preferential treatments of connected groups' (p. 154).

Research has also indicated that, at an institutional level, not all forms of diversity and difference are welcomed in the same way. Moon (2016), for example, argues that Korean universities aggressively recruit international students with diverse ethnic backgrounds, and yet strongly resist any formal institutional commitment to diversity more generally. Indeed, she notes that ethnic nationalism is evident in both higher education curricula and the everyday interactions between foreign and local students. She goes on to argue that this selective adoption of diversity (at a structural level, but not at educational or interactional levels) reflects Korea's highly instrumental approach to globalisation - focussing on only those elements that can help to further its national interest. Similar arguments have been made with respect to Anglophone nations. On the basis of her research in New Zealand and the UK, Bowl (2018) argues that diversity is often used instead of terms such as equality because of its perceived utility in appealing to international students and highlighting the 'international' nature of the student body. While the recruitment of international students may serve to exacerbate inequalities rather than redress them (because of the economically advantaged social position of many of those who are able to move abroad for HE), the use of 
the word 'diversity' is helpful, Bowl maintains, in 'easing the tension between equality and the market' (p.684), conjuring up the idea of a vibrant cultural and ethnic mix while concealing deep-seated inequalities based on race and ethnicity.

Such arguments have much in common with broader points that have been made about changes, evident across the world, in the way in which issues pertaining to social difference are discussed. Banting and Kymlicka (2013), for example, have noted - in relation to ethnic difference in particular - a discursive retreat from the language of 'multiculturalism' in social policies across Europe. They maintain that while there is often considerable continuity in the substantive content of policies themselves, they are now more commonly referred to as 'diversity policies', or 'intercultural dialogue' or 'civic integration', rather than multicultural initiatives. This linguistic shift has significant consequences, Banting and Kymlicka contend - tending to perpetuate stereotypes of immigrants as alien and threatening, and thus contributing to the rise of far-right populist parties, and weakening the support for multicultural policies. Here, there are also points of connection with debates in the sociological literature about the language that is used to discuss ethnic difference. Back and Sinha (2016), for example, have argued that while the concept of 'super-diversity' (originally coined by Vertovec (2007) and subsequently taken up by scholars across the social sciences) is a well-intentioned attempt to value difference positively and develop more complex understandings of contemporary patterns of migration, it downplays: the 'continued social vitality of racism' (p.520); the new racist hierarchies that have emerged in many European states; and the enduring impact of empire. 


\section{Educational institutions as sites for diversity and social mixing}

Alongside discussions about the place of 'diversity' within institutional policies is another body of work that has explored the extent to which educational institutions are, in practice, experienced as diverse places by the students (and, to a lesser extent, staff) who inhabit them. In part, this is informed by the so-called 'convival turn' in the social sciences, which has emphasised the importance of paying attention to the ways in which difference is negotiated on an ordinary, everyday basis in quite routine ways (Neal et al., 2013). Although such arguments have often been made with respect to the urban landscape - suggesting that cities, by virtue of the density and heterogeneity of their populations, facilitate such interactions they have also been advanced in relation to educational institutions. Schools, colleges and universities have been conceived of as spaces of 'habitual contact' in which close interaction between individuals from different backgrounds is facilitated. Indeed, Bennett et al. (2017) have argued that 'the formal processes of learning, delivering the certificates, is accompanied by more informal processes in which students manage and negotiate difference ... Colleges are key sites within which urban multiculture is experienced and through which it is defined' (p.2319). Educational institutions are thus conceived by some as potential 'micro-publics' (Amin, 2002) in which students can encounter difference in productive ways and help to reshape social relations (Harris, 2013; Vincent et al., 2017).

Nevertheless, critics have argued that everyday encounters are not always sufficient to counter long-held prejudices, and that diversity and social mixing can often be perceived in rather different ways by those occupying contrasting social positions (Hemming, 2011; Vincent et al., 2017). Empirical work, within schools, colleges and higher education institutions, has also raised some questions about the extent to which diversity is recognised 
and celebrated, and the capacity such institutions have for reconfiguring relations between different social groups. Marginson (2016) has argued that the worldwide expansion of higher education evident over recent decades has not been accompanied by a concomitant increase in the diversity of student bodies, particularly at elite universities. Stratification - both between and within higher education institutions - has endured, largely because higher education is a positional good, and thus its sorting function is as important as the absolute opportunities it brings (ibid.). Indeed, within the UK, students from state schools and those from black and Asian ethnic groups are significantly less likely to receive an offer from prestigious 'research intensive' universities than their more privileged peers (Boliver, 2013). Moreover, inequalities can also be reproduced amongst those who are successful in securing a higher education place. Within the UK, for example, Andersson et al. (2012) argue that 'encounters across difference' on university campuses are limited by: the impact of institutional arrangements (such as the allocation of accommodation); practices of selfsegregation on the part of students; and also the commercial forces which orientate certain students towards lifestyle choices that exclude others.

Such processes, with respect to diversity, are not, however, played out in the same way across all nation-states. Warikoo's (2016) comparison of admission processes to elite universities in the UK and US, and the views of students attending such institutions in both countries, highlights some key differences. She argues that US institutions place more emphasis than their British counterparts on helping disadvantaged students gain access to elite higher education - partly because progressive social policy in the UK has focussed more on aiding disadvantaged groups directly, rather than expecting education to play the role of a 'social escalator'. Warikoo goes on to contend that these differences in the official narratives surrounding university admissions are reflected in students' ways of seeing the world. The 
UK students in her sample, for example, were less likely than their American peers to view diversity with respect to race and ethnicity as positive aspects of campus life, and more likely to believe that racial and ethnic disadvantage was rooted in group culture rather than a result of discrimination. Warikoo's work provides an important point of departure for this article firstly, in its emphasis on the salience of cross-national differences and, secondly, in its suggestion that institutional policies, practices and assumptions can have a significant bearing on the perspectives taken up by students.

\section{Research methods}

The article draws on an analysis of 26 interviews with 'policy influencers' and, to a lesser extent, 92 policy documents, from six different European countries (Denmark, England, Germany, Ireland, Poland and Spain). The countries were chosen to provide diversity with respect to their: 'welfare regime' (Esping Anderson, 1990); relationship to the European Union (EU); and means of funding higher education (see Table 1). The data were collected as part of a larger project on the ways in which higher education students are understood across Europe, which pays particular attention to similarities and differences both within and between countries. In each country, 4 or 5 semi-structured interviews (lasting about an hour) were conducted with individuals responsible for formulating higher education policy or whose role involved engaging with policymakers and attempting to influence HE policy including at least one person from each of the following groups: government ministry (minister or civil servant); national students' or staff union; organisations representing graduate employers; and organisations representing HEIs ${ }^{\mathrm{i}}$. All interviewees were asked about: how they understood or conceptualised higher education students; how they thought other social actors understood such students; and their views on specific conceptualisations of 
the student (e.g. as a consumer, a political actor and a future worker). They were also asked to respond to an extract from a key policy text from their own country. These extracts were chosen because they contained a construction of HE students that appeared to be common across many relevant higher education policies from that nation, and were typically taken from a high-profile government strategy document. Interviews were conducted in English, audio-recorded, fully transcribed and uploaded to NVivo for analysis. In addition, in each nation approximately 16 policy texts were selected for analysis, comprising speeches given by government ministers for higher education, and key strategy documents, relating to higher education, produced by government, staff and student unions, and organisations representing graduate employers (in most cases, four documents were selected from each of the four groups ${ }^{\mathrm{ii}}$ ). Documents were chosen on the basis of their: national significance; relevance to the project's focus (on higher education students); and date of publication (the most recent documents were chosen from those deemed to be most significant and relevant). Those not available in English were translated prior to analysis. A qualitative analysis was conducted of both the interviews and policy documents, which examined the ways in which particular terms were used, not only their presence or absence. First, all materials were coded - using codes derived, inductively, from the texts themselves, but which were also, in some cases, informed by the extant literature (see Brooks, 2018a, for a discussion of previous empirical and theoretical work on constructions of the higher education student, which informed the analysis). Second, the coded material was used to identify dominant themes across the dataset and make comparisons between the six countries and various different stakeholder groups. The discussion below focuses primarily, although not exclusively, on the interviews, as key themes from the document analysis have been explored elsewhere (see Brooks, 2018b; Brooks, under review). 


\section{Narratives of diversity}

Across the dataset as a whole, various dimensions of difference were mentioned by the policy influencers. They were not, however, all discussed in the same way or attributed the same value. Below, two examples are drawn upon to illustrate this variation, contrasting the explicit valorisation of 'age diversity' in many of the countries with the implicit problematisation of increasing the social class diversity of student bodies in some nations.

\section{Explicit celebration of diversity: age}

As noted above, all of the interviewees were asked an open-ended question about how they understood or conceptualised higher education students before the interview moved on to a series of more specific questions. A striking pattern across the interviews was the way in which diversity with respect to age was highlighted. This dimension of difference was brought up spontaneously by a large proportion of respondents - either because it represented, to their minds, a key aspect of recent change within the higher education sector or an area in which more work was urgently needed. Moreover, age diversity was mentioned much more frequently than other dimensions of difference (such as gender, class, ethnicity, migration background, disability and sexuality), and evaluated in wholly positive terms. (Here, there is a significant contrast with the way in which family background was discussed, which will be explored below.) The following extracts are typical:

you will find more and more students who are not classical students in that sense that I describe, coming straight from secondary education, but mature students who ... in ... an increasing number of cases, have never attended a university before and may not even have the Abituriii $[\ldots .$.$] But compensate for that by their professional experience. And so$ 
universities are beginning to ... open up to this kind of new learner (Germany, HEI representative)

Well I think students in Spain, well in general, I think it's a heterogeneous group because we have like the very young people, just out of ... high ... secondary school, who study full-time and who is financed by their parents [....] And then you have older people, people who work and who would like study because they are interested in a certain area (Spain, HEI representative)

The students are ... overwhelmingly young, they're overwhelmingly straight out of school, they're overwhelmingly younger than their European counterparts, for a number of reasons. (Ireland, HEI representative)

It's everyone, anyone can be a student at any age, any interests, every single person, so between higher education between further education, between lifelong learning, it's very, very broad and it's just probably, you can't really define who a student is. (Ireland, students' union representative)

I think one of the part of being student is being someone young. Because in Poland we have really a high degree of people who study. (Poland, students' union representative)

In the extracts above, there is variation in the extent to which the current student population is viewed as diverse with respect to age. This is notable even within the same country - the students' union representative in Ireland, for example, has a rather different view of the extent to which age diversity has been achieved than the interviewee from the body that represents HEIs. Nevertheless, the salient point is that all respondents discussed this particular social characteristic more explicitly than any other. Moreover, many interviewees 
contrasted what they saw as the greater recognition given to age diversity in contemporary higher education with the relatively neglected status of this dimension in the past:

In Germany, until a couple of years ago, I would say that everyone agreed that a student is someone aged around eighteen, nineteen or twenty, who goes to higher education, right after completing secondary .... And that's been changing, that's, that has started to change a couple of years ago in the sense that ... more and more universities are beginning to offer at least blended learning ... teaching possibilities. (Germany, HEI representative)

$\ldots$ it is really changing. So the access agenda's changed this a lot, the part-time agenda, and really this lifelong learning and upskilling piece started to make us all look at it as a ... continuum, and that we'll actually be going in and out of the higher education system constantly over our lives, you know. (Ireland, government official)

Interviewees also discussed how their own views about age diversity were not necessarily shared by the population as a whole. In the extract below, for example, an interviewee from the organisation that represents UK universities highlighted the dominance of narratives about 'traditional age' students:

I think a lot of people have this perception of eighteen year olds going to university to study full-time for a bachelor's degree, which is clearly a significant proportion of higher education provision in the UK, but it's not, it's not the only higher education provision in the UK, and students are more diverse than that. (England, HEI representative)

In many ways, the frequency with which age was brought up as a significant social category and dimension of difference within the interviews provides a marked contrast with how it has 
commonly been discussed in the academic literature. Scholars have typically pointed out that many HEIs can be difficult to navigate for older learners, and institutional policies and practices remain predicated on the assumption that the vast majority of students come straight from school, bringing with them few external ties or responsibilities (e.g. Mallman and Lee, 2016). Older learners with childcare commitments often face particular difficulties such as late availability of timetables, a lack of nearby childcare facilities, and policies that prohibit children from coming onto campus (Marandet and Wainwright, 2010) - although these differ somewhat by nation-state (Brooks, 2012; Saar et al., 2014). Wider structural factors can also negatively impact on adult students, including: admission arrangements; available modes of study; financial and other support; and the extent of institutional flexibility with respect to course content and organisation (Saar et al., 2014). The data presented above do not necessarily raise questions about any of these findings; they do not suggest that higher education institutions themselves have become more sensitive to age difference, merely that 'policy influencers' view it as a salient dimension of difference and one that should be celebrated and/or encouraged further.

Policymakers' perspectives are clearly influenced, to some extent at least, by the 'assumptive worlds' (Sabri, 2010) in which they move and, more specifically, the national and regional pressures placed upon them to increase the number of older learners. Within the Bologna Process, which has sought to reconfigure higher education across the continent to ensure comparability in the standards and quality of HE qualifications, lifelong learning has been given considerable prominence (Jakobi and Rusconi, 2009). As part of this reform agenda, national governments have been asked to encourage their universities to develop flexible learning pathways, establish alternative routes to higher education, and create opportunities for the recognition of prior learning - underpinned by a belief that institutions need to do 
more to enable adult access to HE (Saar et al., 2014). It is perhaps unsurprising, given this wider context, that age is the social characteristic that a wide range of policy influencers foregrounded within their narratives.

National imperatives are also significant. For example, in Poland, as a result of the sharp demographic decline in the number of 'younger learners' (i.e. those in their late teens and early 20s $)^{\text {iv }}$, older learners have been sought as a means of shoring up the higher education sector and ensuring the ongoing viability of some HEIs (Łukasiewicz, 2014). More generally, however, the valorisation of older learners - amongst policymakers at least - articulates with the reorientation of the higher education sector around the needs of the economy (Collini, 2012; Slaughter and Rhoades, 2004). Many of our interviewees articulated this link explicitly:

it [focus on older learners] has advantages, of course, for the companies [....] because the idea is that in universities you have the research at the edge, so you get the new things into your society. (Germany, government official)

the competition's increasing, globally [....] we need to, to preserve and keep our wealth in Denmark. We need to be in the front in so many different areas. And I think that higher education is a way of providing the raw material for that. (Denmark, government official)

And we're about to try to ... move away from our sole focus on school leavers and the unemployed, into now a much wider ... view of who should be learners. .... We've paid insufficient attention to upskilling those at work. (Ireland, government official) 
Thus, while age diversity was celebrated by many of the interviewees, this was typically not grounded within a social justice perspective, but one that prioritised the needs of the labour market. These narratives reflect in some respects the ways in which adult education, itself, has been reconceptualised over the past half-century. There is now a large body of work, stretching over numerous national contexts, that has evidenced how the education of older learners, particularly within higher education, has taken on a strongly economistic focus, driven by the desire to ensure that there is a good match between the skills of adults and those required by the labour market, and moved away from its more radical roots that emphasised the role of adult education in promoting social inclusion and democratic participation (Slowey and Scheutze, 2012).

\section{$\underline{\text { Implicit problematisation of diversity: social class }}$}

As noted above, very few other dimensions of difference were mentioned explicitly by respondents when they were asked to talk about their understandings of higher education students - or indeed when they were asked directly about differences between students. Nevertheless, many of the narratives made implicit reference to the social class of students, primarily in terms of their family background. Such references were typically made in discussions about changes to the higher education sector generally, rather than the characteristics of students specifically.

In both the interviews and policy texts, it was recognised that, in all the countries in the study, the national body of higher education students had become increasingly diverse, with respect to family background, over recent years. Although some interviewees claimed that this was related to specific schemes to increase the participation of particular groups of students, in 
general, it was seen as a direct consequence of processes of massification. While the increased diversity of the student population was remarked on by a majority of our interviewees and mentioned in many of the documents, there were significant national differences in how this diversity was evaluated. In several nations, problems associated with massification were identified, which were directly or indirectly linked to increasing diversity by social class. Several interviewees highlighted the challenges to traditional methods of teaching posed by more socially diverse (and often considerably larger) student bodies. Others problematised in more explicit terms the attitudes to learning evident in more diverse bodies, claiming, for example, that students without a family history of higher education had more passive approaches to learning and a more instrumental view of education:

I believe ... the universities have some anxiety or feel that, that I mean that we risk going from being students to being more like pupils in the way that when you have that ... greater intake of students, you also have a broader ... they have a broad social background and different backgrounds and some of them might demand more ... more teaching and ... and perhaps more structured teaching, instead of that you have to take responsible yourself for your learning .... but there is a, maybe there is a shift from the ... original meaning of student, as I see it. (Denmark, HEI representative)

... with the massive increase in intake during the last less than ten years, is there some way that we have taken in too many, basically have we actually lowered the expectations because we just wanted more people to get in? ... there might just be some problems here about are they actually qualified for doing this kind of studying? It might be they should do something else ... in some other areas. ... when we have a diverse student group, what do you do? (Denmark, government official) 
Students now are perceived, or at least I perceive them largely in this way, as simply people who, who seek our qualifications to ... go on the labour market. (Poland, government official)

In the second quotation above, the Danish government official goes as far as to question whether the more 'diverse' group of students should be at university at all. In addition, some respondents problematised the wider characteristics of non-traditional students. In the extract below, for example, an interviewee from the Polish education ministry not only comments on the more instrumental focus of many contemporary students but also laments their lack of interest in and engagement with social and political issues.

I kind of miss the times when being a student meant being part of an elite that also sort of assumes the role of, of agents that work for positive change, that evaluate the reality behind the [rhetoric] and try to have an influence or to have an impact on it, to influence it, in order to push it towards a better, a better ... better ... solutions, outcomes. .... there's just focus on their professional careers, on how they fare economically and ... total disregard, maybe not total, but very little regard for things that are definitely important. (Poland, government official)

Narratives such as these differ from those relating to age in several important respects. Firstly, social class is typically discussed more obliquely. Various respondents talk about changes to the student body, but the link to social class often remains unsaid. For example, in the quotation above, it is not stated explicitly that the students who focus solely on their career and ignore wider social issues are those from lower socio-economic groups. Nevertheless, because the extract starts with a lament for times when only an elite progressed to higher education, the discussion is framed in terms of class - rather than, for example, explaining the change in students' attitudes in terms of wider shifts in society and/or the 
economy. This implicit referencing of social class contrasts markedly with the clarity with which age differences are discussed. Secondly, unlike the discussion of age, changes with respect to social class/family background are not always evaluated positively. This is evident in all the quotations above, which identify a mismatch between the approaches to learning and attitudes of the 'massified' student body, on the one hand, and traditional conceptions of higher education on the other. While in some cases, this has led to the re-thinking of pedagogical approaches and the orientation of universities, in the extracts above it is primarily students rather than institutions that are subject to critical scrutiny. Here, there are broad parallels with research that has focussed on institutional practices which has argued that working class students are often seen as 'deficient' within universities (Loveday, 2016), and that academic cultures often privilege middle class identities and habituses (Bathmaker et al., 2013; Thomsen, 2012; Reay et al., 2010).

Finally, there is considerable national variation in the ways in which students from lower socio-economic groups are discussed. It is notable that they are problematised most by policy influencers from Poland and Denmark, illustrated by the quotations above. This articulates with a broader argument we have made elsewhere (Brooks, under review) about the extent to which students are constructed as 'objects of criticism' in the six countries in this study. We have argued that there are considerable differences across the policy documents, specifically, with respect to the extent to which students are criticised, which relate to the broader political and policy context. For example, students are criticised least in English policy - largely, we suggest, because the state is dependent on the high fees they pay (see Table 1) to ensure the sustainability of the sector, thus alienating this group (through criticism) would presumably be considered a highly risky governmental strategy. In contrast, in Poland and Denmark, where full-time students are fully-funded by the state (see Table 1), concerns are more likely 
to focus on ensuring students fulfil their responsibilities with respect to learning and that taxpayers continue to deem that the size and shape of the overall student population is appropriate and well-aligned to national needs. Such arguments appear equally relevant to understanding the differences in the narratives of the policy influencers.

\section{Discussion and conclusion}

As this article has analysed data from policymakers and influencers only, it cannot provide any evidence about whether the ways in which diversity is talked about by interviewees and in the policy texts have had any depoliticising effects in practice (either in individual higher education institutions or across national HE sectors), in the ways discussed by scholars such as Ahmed (2007), Bowl (2018) and Deem and Morley (2006). Nevertheless, the focus on age as a primary characteristic of difference, and the strong association between this and labour market concerns, suggests, firstly, that diversity appears to be understood in highly circumscribed terms and, secondly, that - like the policy interventions examined in other studies and discussed at the start of this article - it is not driven by a social justice agenda.

Moreover, reflecting previous research in this area, the evidence presented above from policy influencers indicates that aspects of diversity continue to be adopted very selectively. While Moon (2016) and Bowl (2018) argued that, in the institutions in their studies, it was cultural and/or national difference that was foregrounded - through the celebration of international students - in this study, age diversity was prioritised. As outlined in the preceding discussion, this was the only dimension of difference that was mentioned explicitly across all six national contexts and by a variety of different policy actors within each nation-state. Indeed, it appears from many of the policy influencers' narratives that age was focussed on for similarly 
instrumental reasons as international students in the earlier research - primarily as a means of pursuing what was held to be the national interest (in this case, ensuring a closer relationship between the higher education sector and the needs of employers). While the salience given to age, as a social characteristic, is a welcome corrective to assumptions that have long been documented across most national higher education sectors about the 'young' biological age of students - and the policies that flow from these, which often serve to exclude those of an older age (Mallman and Lee, 2016) - its association with an economistic agenda suggests that it is unlikely to help drive through a more structural analysis of difference and inequality. Commitment to this one aspect of diversity does not ensure that other aspects will be treated similarly. This is made apparent in the way in which social class was discussed, and implicitly or explicitly problematised, by a number of our interviewees, outlined above.

Similarly, although the research presented in this article is not able to shed any light on the extent to which HEIs across the six countries do, in practice, promote social mixing and act as the 'micro publics' discussed by Bennett et al. (2017), Amin (2002) and Harris (2013), it has suggested that policy influencers, at least, rarely conceive universities in this way. Indeed, as indicated above, in some countries the disadvantages of class mixing were emphasised much more than the advantages - pointing to, for example, the pedagogical challenges of educating more socially mixed cohorts and the increasingly narrow understanding of what it means to be a university student held, it was alleged, by those with no previous family experience of higher education. Moreover, even when age was discussed in positive terms, this was in relation to the future value of educating older learners and the impact on work, employment and the economy, rather than on the composition of higher education institutions and everyday campus interactions. 
Policy positions are important, as Warikoo's (2016) work has suggested, as assumptions made at the level of national policy and/or institutional management can inform those taken up by students, on the ground, and can also delineate who is perceived to be welcome on campus and who is not. While the explicit emphasis on and celebration of age diversity is to be welcomed, the lack of a similar degree of attention to other dimensions of difference across the sample as a whole, and the implicit problematisation of social class diversity, within some nations at least, suggests that not all students may feel equally welcome on campus. The wider project, of which this strand of enquiry is a part, will bring data to bear on this issue, by interrogating the degree of consensus between the understandings of policy influencers and the everyday experiences and perspectives of higher education students across Europe.

\section{Acknowledgements}

I would like to thank the European Research Council for the award of a Consolidator Grant (reference 681018_EUROSTUDENTS), which funded this research. I am also very grateful to the individuals who gave up their time to be interviewed for this study.

\section{References}

Ahmed, S. (2007) The language of diversity, Ethnic and Racial Studies, 30, 2, 235-256.

Amin, A. (2002) Ethnicity and the multi-cultural city: living with diversity, Environment and Planning A, 34, 959-980. 
Andersson, J., Sadgrove, J. and Valentine, G. (2012) Consuming campus: geographies of encounter at a British university, Social and Cultural Geography, 13, 5, 501-515.

Back, L. and Sinha, S. (2016) Multicultural conviviality in the midst of racism's ruins, Journal of Intercultural Studies, 37, 5, 517-532.

Banting, K. and Kymlicka, W. (2013) Is there a retreat from multiculturalism policies? New evidence from the multiculturalism policy index, Comparative European Politics, 11, 5, 577 598.

Bathmaker, A., Ingram, N. and Waller, R. (2013) Higher education, social class and the mobilisation of capitals: recognising and playing the game, British Journal of Sociology of Education, 34, 5-6, 723-743.

Bennett, K., Cochrane, A., Mohan, G. and Neal, S. (2017) Negotiating the educational spaces of urban multiculture: skills, competences and college life, Urban Studies, 54, 10, 2305-2321.

Boliver, V. (2013) How fair is access to more prestigious UK Universities? British Journal of Sociology 64, 2, 344-364.

Bowl, M. (2018) Differentiation, distinction and equality - or diversity? The language of the marketised university: an England, New Zealand comparison, Studies in Higher Education, 43, 4, 671-688. 
Brooks, R. (2012) Student-parents and higher education: a cross-national comparison, Journal of Education Policy 27, 3, 423-437.

Brooks, R. (2018a) Understanding the higher education student in Europe: a comparative analysis, Compare: A Journal of Comparative and International Education, 48, 4, 500-517.

Brooks, R. (2018b) Higher education mobilities: a cross-national European comparison, Geoforum, 93, 87-96.

Brooks, R. (under review) The construction of higher education students within national policy: a cross-European comparison

Collini, S. (2012) What are Universities For? London, Penguin Books.

Deem, R. and Morley, L. (2006) Diversity in the academy? Staff perceptions of equality policies in six contemporary higher education institutions, Policy Futures in Education, 4, 2, $185-202$

Epsing-Anderson, G. (1990) The Three Worlds of Welfare Capitalism Cambridge, Polity Press.

Eurydice (2017) National Student Fee and Support Systems in European Higher Education 2017/18 Available online at: https://eacea.ec.europa.eu/nationalpolicies/eurydice/content/national-student-fee-and-support-systems-european-highereducation-\%E2\%80\%93-201718_en (Accessed 08/08/18). 
Harris, A. (2013) Young People and Everyday Multiculturalism New York, Routledge.

Hemming, P. (2011) Meaningful encounters? Religion and social cohesion in the English primary school, Social and Cultural Geography, 12, 1, 63-81.

Jakobi, A.P. and Rusconi, A. (2009) Lifelong learning in the Bologna process: European development in higher education, Compare, 39, 1, 51-65.

Klein, U. (2016) Gender equality and diversity politics in higher education: conflicts, challenges and requirements for collaboration, Women's Studies International Forum, 54, 147-156.

Loveday, V. (2015) Working class participation, middle class aspiration? Value, upward mobility and symbolic indebtedness in higher education, The Sociological Review, 63, 3, 570588.

Loveday, V. (2016) Embodying deficiency through 'affective practice': shame, relationality, and the lied experience of social class and gender in higher education, Sociology, 50, 6, 11401155.

Łukasiewicz, A. (2014) Nowi studenci są ciut starsi (New students are slightly older), Gazeta Wyborcza, 29 January 2014. 
Mallman, M. and Lee, H. (2016) Stigmatised learners: mature-age students negotiating university culture, British Journal of Sociology of Education, 37, 5, 684-701

Marandet, E. and Wainwright, E. (2010) Invisible experiences: understanding the choices and needs of university students with dependent children, British Educational Research Journal, $36,5,787-805$.

Marginson, S. (2016) The worldwide trend to high participation higher education: dynamics of social stratification in inclusive systems, Higher Education, 72, 413-434.

Moon, R. (2016) Internationalisation without cultural diversity? Higher education in Korea, Comparative Education, 52, 1, 91-108.

Neal S., Bennett, K., and Cochrane A. (2013) Living multiculture: Understanding the new spatial and social relations of ethnicity and multiculture in England, Environment and Planning C 31, 2, 308-323.

Pérez Cañado, M. 92015) Democratization in European higher education: the past, present and future of the Bologna Process, in: Blessinger, P. and Anchan, J. (eds) Democratizing Higher Education. International Comparative Perspectives New York, Routledge.

Reay, D., Crozier, G. and Clayton, J. (2010) 'Fitting in' or 'standing out': working class students in UK higher education, British Educational Research Journal, 36, 1, 107-124. 
Saar, E., Täht, K. and Roosalu, T. (2014) Institutional barriers for adults' participation in higher education in thirteen European countries, Higher Education, 68, 691-710.

Sabri, D. (2010) Absence of the academic from higher education policy, Journal of Education Policy, 25, 2, 191-205.

Slaughter, S. and Rhoades, G. (2004) Academic Capitalism and the New Economy: Markets, State and Higher Education Baltimore, MD, John Hopkins University Press.

Slowey, M. and Schuetze, H. (eds) (2012) Global Perspectives on Higher Education and Lifelong Learners London, Routledge.

Talib, N. and Fitzgerald, R. (2015) Inequality as meritocracy, Critical Discourse Studies, 12, $4,445-462$.

Thomsen, J.P. (2012) Exploring the heterogeneity of class in higher education: social and cultural differentiation in Danish university programmes, British Journal of Sociology of Education, 33, 4, 565-585.

Vertovec, S. (2007) Super-diversity and its implications, Ethnic and Racial Studies, 30, 6, $1024-1054$.

Vincent, C., Neal, S. and Iqbal, S. (2017) Encounters with diversity: children's friendships and parental responses, Urban Studies, 54, 8, 1974-1989. 
Warikoo, N. (2016) The Diversity Bargain and other Dilemmas of Race, Admissions, and Meritocracy at Elite Universities Chicago, University of Chicago Press.

Wilkins, A. and Burke, P.J. (2015) Widening participation in higher education: the role of professional and social class identities and commitments, British Journal of Sociology of Education, 36, 3, 434-452.

\footnotetext{
i These various groups are referred to as follows when they are quoted in the discussion: Government official; Union representative; Employer representative; and HEI representative.

ii In Poland, no relevant employer documents were identified. Thus, the Polish sample comprises only 12 documents.

iii This is a German qualification which facilitates entry to higher education. It is taken by students at the end of secondary education.

iv This demographic decline has been due to a declining birth rate in Poland and an increase in emigration.
} 